\title{
Antenatal care in primary health care centres in Medina, Saudi Arabia, 2009: a cross-sectional study
}

\author{
F. Habib, M.I. Hanafi ${ }^{2}$ and A. El-Sagheer ${ }^{3}$
}

$$
\begin{aligned}
& \text { الرعاية السابقة للولادة في مراكز الرعاية الصحية الأولية في المدينة المنوّرة في المملكة العربية السعودية، لعام 2009: دراسة } \\
& \text { مُسْتعر ضَّة } \\
& \text { فوزية حَبيب، منال إبراهيم حنفي، عائشة الصغير }
\end{aligned}
$$

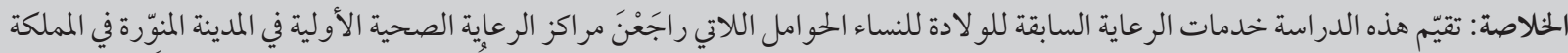

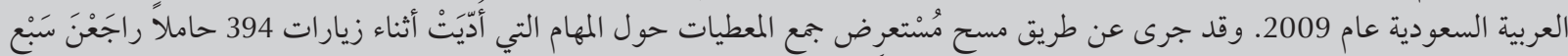

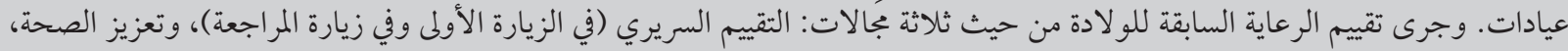

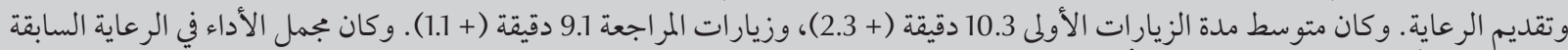

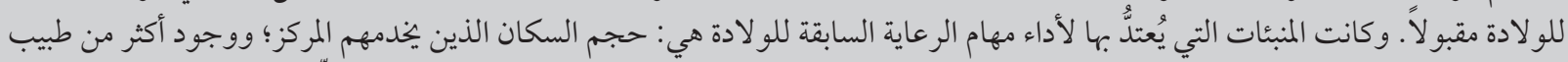

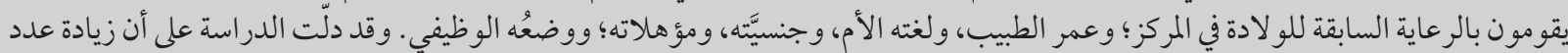

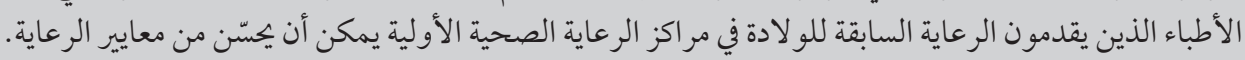

ABSTRACT This study evaluated antenatal care (ANC) services for pregnant women attending primary health care centres in Medina city, Saudi Arabia in 2009. A cross-sectional survey collected data on ANC tasks performed at visits by 394 pregnant women attending 7 clinics. ANC was assessed in 3 domains: clinical assessment (at the initial visit and return visit), health promotion and care provision. The mean duration of initial visits was 10.3 (SD 2.3) minutes and of return visits was 9.1 (SD 1.1) minutes. Overall performance on ANC tasks was fair. The significant predictors of ANC performance of tasks were: size of population served per centre; presence of more than 1 physician carrying out ANC at the centre; physician's age, mother tongue, nationality and qualifications; and woman's education and employment status. Having more physicians available for ANC in primary care centres could improve the standard of care.

Soins prénatals dans les centres de soins de santé primaires à Médine (Arabie saoudite) en 2009 : étude transversale RÉSUMÉ La présente étude a évalué les services de soins prénatals destinés aux femmes enceintes consultant dans des centres de soins de santé primaires de la ville de Médine, en Arabie saoudite, en 2009. Dans le cadre d'une enquête transversale, des données ont été recueillies sur les actes de soins prénatals réalisés lors des visites de 394 femmes enceintes consultant dans sept centres. Les soins prénatals ont été évalués en fonction de trois axes : I'examen clinique (lors de la première et de la deuxième visite), la promotion de la santé et la prestation de soins. La durée moyenne des premières visites était de 10,3 minutes (E.T. 2,3) et de 9,1 minutes pour les deuxièmes visites (E.T.1,1). La performance globale pour les actes de soins prénatals était acceptable. Les facteurs prédictifs importants pour la performance des actes de soins prénatals étaient les suivants : la taille de la population couverte par centre ; la présence de plus d'un médecin dispensateur de soins prénatals au centre ; l'âge du médecin, sa langue maternelle, sa nationalité et ses qualifications ; et le niveau d'instruction de la patiente et sa situation professionnelle. Le fait de disposer de davantage de médecins pour dispenser des soins prénatals dans des centres de soins de santé primaires pourrait améliorer la qualité des soins.

'Department of Obstetrics and Gynaecology, College of Medicine, Taibah University, Medina, Saudi Arabia.

${ }^{2}$ Department of Community Medicine, Faculty of Medicine, University of Alexandria, Alexandria, Egypt (Correspondence to M.I. Hanafi: manal. azab@gmail.com).

${ }^{3}$ Ministry of Health, Medina, Saudi Arabia.

Received: 07/07/09; accepted: 30/08/09 


\section{Introduction}

Promotion of maternal and fetal health necessitates proper antenatal care (ANC) that includes health education, such as parenthood and family life education, counselling, screening and treatment $[1,2]$. Many health problems that threaten pregnant women's health can be managed through improved ANC in which proper discussions, taking account of the intellectual, emotional, social and cultural needs of women, infants and families, will be accompanied by appropriate decisions for individual pregnancy care [3-5]. The components of an ANC package should be designed to be effective, acceptable and of high quality together with proper selection of clinical examinations and laboratory tests.

The World Summit for Children in 1990, the International Conference on Population and Development in 1994 and the Fourth World Conference on Women in 1995 all promoted the goal of ANC being available to all pregnant women, with childbirth by trained birth attendants and proper referral systems for high-risk pregnancies [6]. The model of ANC from developed countries has been adopted by most developing countries albeit with slight modifications $[7,8]$. The World Health Organization (WHO) has recommended that ANC for normal pregnancies should involve 4 antenatal visits and has outlined the key elements and timing of visits [9]. The components of ANC for a normal pregnancy have been described under 3 main categories: assessment (history, examination and laboratory tests), health promotion and care provision.

Most currently used models of ANC have not been subjected to evaluation. In developing countries, there is poor implementation of ANC programmes, with irregular visits, long waiting time and poor feedback to women [10]. Due to the scarcity of research about the quality of ANC in Saudi Arabia, a study was carried out to evaluate the ANC services given for pregnant women attending primary health care centres (PHCCs) in Medina city. The aim of the study was to analyse the pattern of consultations at the health centres and the characteristics of the physicians and the women and to determine the predictors of good ANC performance.

\section{Methods}

A cross-sectional survey was conducted during March to July 2009.

\section{Sample and setting}

The study population was pregnant women attending PHCCs in Medina, Saudi Arabia for ANC over the study period. Simple random selection of 7 major PHCCs in Medina was done. The total number of pregnant women included in the study was calculated using the following equation: $n=\left(z^{2} \times\right.$ $p \times q) / D^{2}$, where $z=1.96, p=0.16, q=$ $0.84, d=0.05$. The sample size was thus estimated to be 394 pregnant women. The populations served by the centres ranged from 10000 to 35000 and the number of women were proportionally allocated based on the number of pregnant women served by each centre (range of women per health centre from 32 to 90). Each centre selected was visited twice a week and all pregnant women who visited the centre on that day were included until the required sample size was reached. None of the women refused to participate.

\section{Data collection}

A structured data collection form was specially designed for the study using WHO criteria for ANC [11]. The researcher visited each centre and completed the checklist during observations of observed ANC visits without any discussions with the attending physicians or women or any review of records.

The form was used to collect data about the education and work status of the pregnant woman, and some sociodemographic data about of the physician (nationality, mother tongue, qualifications and age). The time spent for each ANC visit was documented and then data were collected in 3 domains: clinical assessment (at the initial visit and return visit); health promotion; and care provision. Each of the items of antenatal tasks was scored 0 (if not performed) or 1 (if performed) as follows:

- Assessment (initial visit): wantedness of pregnancy, social history and support, history of female genital mutilation (FGM), general appearance, clinical signs of anaemia, signs of physical abuse, breast examination, thyroid examination; varicose veins examination. Score ranges: history taking: 0-21; examination: $0-12$; laboratory investigations: $0-11$.

- Assessment (return visit): social, family and community support, general appearance, clinical signs of anaemia, signs of physical abuse. Score ranges: history taking: $0-3$; examination: $0-9$.

- Health promotion: nutritional advice; rest; hygiene; safe sex; planning for delivery; counselling on referral hospital transportation and blood transfusion; counselling on newborn care including breastfeeding; family planning and child spacing; smoking. Score range: $0-10$.

- Care provision: development of an individualized delivery plan; psychosocial support. Score range: 0-6.

The total performance score was calculated for each task at each centre and the mean percentage score was calculated.

Collection of data from the selected centres was done after obtaining official permission. The ethics review committee at the University of Alexandria, Faculty of Medicine reviewed and approved the proposal. The survey tool was pre-tested on a random sample of 35 participants obtained from 2 centres 
to ensure the practicability, validity and interpretation of responses. The reliability of the questionnaire was assessed using Cronbach alpha $(\mathrm{a}=0.81)$.

\section{Analysis}

SPSS, version 10 was used for analysis. Frequencies, percentages and arithmetic mean and standard deviation (SD) were calculated. Statistical analyses were done using chi-squared tests and Student $t$-test. Correlation coefficients (linear regression) were used to determine the predictors of good ANC performance. $P$-value $<0.05$ was considered statistically significant.

\section{Results}

\section{Description of the practices and physicians}

A total of 7 PHCCs were included in the study and 394 pregnant women attending for ANC consultation were recruited. More than half of the physicians (57.1\%) were Egyptian, 28.7\% were Pakistani and 14.2\% Bangladeshi. Their mean age was 45.7 (SD 4.7) years.

\section{Characteristics of the sample of pregnant women}

A minority of the pregnant women studied were illiterate $(0.8 \%)$ (Table 1$)$, while $41.4 \%$ had completed secondary education and $33.2 \%$ had university education. Only $14.0 \%$ of women were working $(P<0.001)$. Regarding duration of pregnancy, $34.4 \%$ were in the 1 st trimester, $36.3 \%$ in the 2 nd trimester and $29.4 \%$ in the $3 r d$ trimester. Around half $(51.5 \%)$ were visiting the centre for the first time. The mean duration of initial visits was 10.3 (SD 2.3) $\mathrm{min}$ and of return visits was 9.1 (SD 1.1) $\mathrm{min}$.

\section{Performance of ANC tasks}

Table 2 shows the \% scores of ANC tasks performed at visits. The lowest percentage coverage was for social history and support, history of FGM, examination of general appearance, breast examination, examination for signs of physical abuse, planning for delivery and development of individualized delivery plan, smoking history and psychosocial support.

\section{Assessment of ANC services}

At the initial visits the mean percentage score for history taking at the PHCCs $[93.4 \%$ (SD 1.5\%)] was higher than at the return visit $[83.0 \%$ (SD 5.4\%)] (Table 3). Clinical examinations, however, were performed better at the return visit than the initial visit [mean scores $86.1 \%$ (SD 7.7\%) and 75.6\% (SD 11.7\%) respectively]. Health promotion had the worst score $[64.9 \%$ (SD 12.7\%)]. The overall total mean percentage score for ANC services was 77.1\% (SD 1.1\%).

\section{Predictors of ANC performance}

Table 4 shows that younger, Arabic speaking, better qualified physicians attained better ANC performance scores, especially for health care promotion.

The significant predictors of performance of ANC tasks were: size of population served per centre; presence of more than 1 physician carrying out ANC at the centre; physician's age, mother tongue, nationality and qualifications; and woman's education and employment status (Table 5).

\section{Discussion}

Our results show that three-quarters of the pregnant women attending for ANC had secondary (41.4\%) or university $(33.2 \%)$ education. It has been noted that in developing countries as a whole, women with secondary or higher education are more likely to attend for ANC than women with no education [12]. We also found that the educational level and work status of the attending pregnant women correlated positively with ANC performance at the studied centre.

Around one-third of the studied pregnant women were attending the PHCC during the first trimester. The early initiation of ANC is important to prevent and treat anaemia and to identify and manage women with medical complications. Early care also allows for the development of interpersonal relationships between the health care

\begin{tabular}{|c|c|c|}
\hline Variable & No. of women & $\%(n=394)$ \\
\hline \multicolumn{3}{|l|}{ Educational level } \\
\hline Illiterate/read and write & 3 & 0.8 \\
\hline Primary & 33 & 8.4 \\
\hline Preparatory & 64 & 16.2 \\
\hline Secondary & 163 & 41.4 \\
\hline University & 131 & 33.2 \\
\hline \multicolumn{3}{|l|}{ Employment status } \\
\hline Not working & 320 & 81.2 \\
\hline Working & 55 & 14.0 \\
\hline Student & 19 & 4.9 \\
\hline \multicolumn{3}{|l|}{ Order of the visit } \\
\hline Initial & 203 & 51.5 \\
\hline Return & 191 & 48.5 \\
\hline \multicolumn{3}{|l|}{ Trimester of pregnancy } \\
\hline 1 st & 135 & 34.3 \\
\hline 2nd & 143 & 36.3 \\
\hline $3 r d$ & 116 & 29.4 \\
\hline
\end{tabular}




\begin{tabular}{|c|c|c|c|}
\hline \multirow[t]{3}{*}{ Domain/task } & \multicolumn{3}{|c|}{$\%$ of ANC visits where task performed } \\
\hline & \multirow{2}{*}{$\begin{array}{l}\text { All health centres } \\
\qquad(n=7)\end{array}$} & \multicolumn{2}{|c|}{ Range } \\
\hline & & Min. & Max. \\
\hline \multicolumn{4}{|l|}{ Assessment: initial visit } \\
\hline Clinical signs of anaemia & 42.9 & 0.0 & 100.0 \\
\hline Thyroid examination & 34.5 & 0.0 & 100.0 \\
\hline Signs of physical abuse & 24.1 & 0.0 & 96.8 \\
\hline Varicose veins examination & 24.1 & 0.0 & 100.0 \\
\hline Wantedness of pregnancy & 10.3 & 0.0 & 61.3 \\
\hline Breast examination & 8.9 & 0.0 & 100.0 \\
\hline Social history and support & 9.9 & 0.0 & 61.3 \\
\hline General appearance & 3.9 & 0.0 & 100.0 \\
\hline History of FGM & 0.0 & 0.0 & 0.0 \\
\hline \multicolumn{4}{|l|}{ Assessment: return visit } \\
\hline General appearance & 42.9 & 0.0 & 100.0 \\
\hline Clinical signs of anaemia & 35.6 & 0.0 & 100.0 \\
\hline Signs of physical abuse & 8.4 & 0.0 & 51.6 \\
\hline Social, family and community support & 2.1 & 0.0 & 12.5 \\
\hline \multicolumn{4}{|l|}{ Health promotion } \\
\hline Nutritional advice & 63.7 & 15.6 & 100.0 \\
\hline Rest & 43.1 & 14.5 & 100.0 \\
\hline Counselling on newborn care including breastfeeding & 39.8 & 4.4 & 100.0 \\
\hline Counselling on referral hospital transportation and blood transfusion & 23.4 & 0.0 & 100.0 \\
\hline Family planning and child spacing & 18.8 & 0.0 & 90.3 \\
\hline Hygiene & 15.5 & 0.0 & 62.9 \\
\hline Safer sex & 10.4 & 0.0 & 53.2 \\
\hline Planning for delivery & 5.8 & 0.0 & 7.3 \\
\hline Smoking & 5.3 & 0.0 & 21.9 \\
\hline \multicolumn{4}{|l|}{ Care provision } \\
\hline Psychosocial support & 2.0 & 0.0 & 14.5 \\
\hline Development of individualized delivery plan & 0.5 & 0.0 & 3.6 \\
\hline
\end{tabular}

$F G M=$ female genital mutilation .

provider and the pregnant woman $[13,14]$.

Scores on tasks performed at the ANC visit ranged widely across different health centres, from zero to $100 \%$ of ANC visits. The best performed tasks overall were in the health promotion domain: nutritional advice (performed at $63.7 \%$ of ANC visits at all health centres), rest (43.1\%) and counselling on newborn care including breastfeeding (39.8\%). Health promotion for a woman can improve her own health and that of her child and the risks of maternal and perinatal complications can
Table 3 Mean percentage score for the 3 domains of antenatal care services assessed

\begin{tabular}{lccc} 
Domain/service & \multicolumn{2}{c}{ Mean (SD) performance scores } \\
& $\begin{array}{c}\text { All health centres } \\
(n=7)\end{array}$ & Min. & Man. \\
Assessment: initial visit & & & \\
History & $93.4(1.5)$ & $92.9(0.0)$ & $95.8(2.4)$ \\
Examination & $75.6(11.7)$ & $66.0(5.3)$ & $95.8(4.3)$ \\
Investigation & $95.0(1.4)$ & $91.3(1.3)$ & $95.5(0.0)$ \\
Assessment: return visit & & & \\
History & $83.0(5.4)$ & $73.1(16.1)$ & $85.4(5.6)$ \\
Examination & $86.1(7.7)$ & $80.8(9.0)$ & $92.9(5.0)$ \\
Health promotion & $64.9(12.7)$ & $53.8(7.6)$ & $83.5(5.3)$ \\
Care provision & $83.0(3.6)$ & $77.9(9.7)$ & $84.8(3.2)$ \\
Total & $77.1(1.1)$ & $68.6(3.2)$ & $88.6(1.3)$ \\
\hline
\end{tabular}

$S D=$ standard deviation 


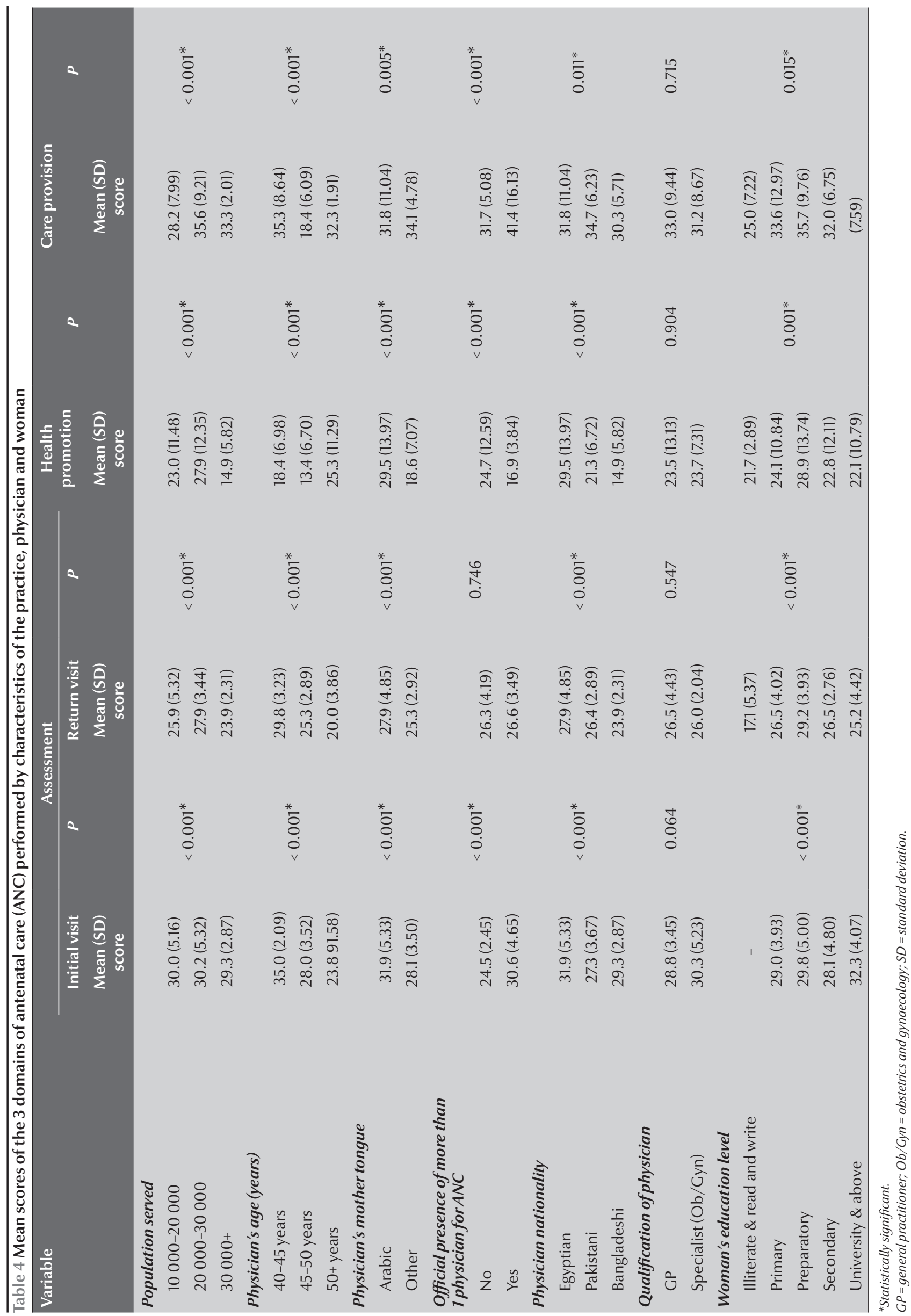




\begin{tabular}{|c|c|c|c|}
\hline \multicolumn{4}{|c|}{$\begin{array}{l}\text { Table } 5 \text { Significant predictors for performance of the } 3 \text { domains of antenatal care } \\
\text { (ANC) performed }\end{array}$} \\
\hline Variable & SE & Beta & $t$-value \\
\hline \multicolumn{4}{|l|}{ Assessment: initial visit (history/examination) } \\
\hline Size of served population & 0.0 & 0.3 & 4.3 \\
\hline Physician's age & 0.3 & 1.1 & 12.1 \\
\hline Physician's mother tongue & 0.9 & 0.7 & 2.5 \\
\hline \multirow[t]{2}{*}{ Presence of more than 1 physician for ANC } & 2.4 & 0.2 & 2.3 \\
\hline & \multicolumn{3}{|c|}{$R^{2}=0.580 ; F=45.085$} \\
\hline \multicolumn{4}{|l|}{ Assessment: return visit (history/examination) } \\
\hline Physician's qualifications & 0.1 & -1.3 & -9.5 \\
\hline Physician's mother tongue & 0.1 & -1.5 & -5.6 \\
\hline \multirow[t]{2}{*}{ Presence of more than 1 physician for ANC } & 0.3 & -0.9 & -10.3 \\
\hline & \multicolumn{3}{|c|}{$R^{2}=0.593 ; F=40.644$} \\
\hline \multicolumn{4}{|l|}{ Health promotion } \\
\hline Population served & 0.0 & -0.3 & -2.7 \\
\hline Woman's education level & 0.0 & 0.1 & 2.4 \\
\hline Physician's age & 0.0 & 0.4 & 2.9 \\
\hline Physician's mother tongue & 0.0 & 1.3 & 4.2 \\
\hline \multirow[t]{2}{*}{ Presence of more than 1 physician for ANC } & 0.0 & 1.3 & 10.4 \\
\hline & \multicolumn{3}{|c|}{$R^{2}=0.604 ; F=22.642$} \\
\hline \multicolumn{4}{|l|}{ Care provision } \\
\hline Woman's employment status & 0.3 & 0.2 & 2.8 \\
\hline Physician's age & 0.1 & -1.6 & -10.6 \\
\hline Physician's nationality & 0.8 & -0.6 & -2.8 \\
\hline Physician's mother tongue & 0.2 & -0.8 & -2.7 \\
\hline \multirow[t]{2}{*}{ Presence of more than 1 physician for ANC } & 0.4 & -0.8 & -7.2 \\
\hline & \multicolumn{3}{|c|}{$R^{2}=0.628 ; F=25.028$} \\
\hline
\end{tabular}

$S E=$ standard error .

be reduced. Yet in developing countries ANC is often poorly implemented [15-22]. In terms of assessment at the initial visit, the tasks most commonly performed were clinical signs of anaemia (performed at $42.9 \%$ of ANC visits overall) and thyroid examination (34.5\%), while in the assessment at the return visit the highest scores were for general appearance (42.9\%) and clinical signs of anaemia (35.6\%). Some items were just recorded as NAS [no abnormal signs], even without conducting an examination, even though these are listed on the maternal record cards used in the PHCCs: general appearance (done for $3.9 \%$ of initial ANC visits) and breast examination (done for $8.9 \%$ ). Social history and support, history of FGM, examination of general that is used in these PHCCs. The fact that deliveries are not allowed outside hospitals in Saudi Arabia, and therefore all pregnant women are referred to maternity hospitals for delivery, means that physicians are less likely to initiate a discussion of the delivery plan.

The physician is the crucial person in the process of ANC. Availability of more than 1 physician to carry out ANC in the PHCC was a determinant of good ANC in this study. Having only 1 physician for ANC services in a large PHCC is unlikely to meet the recommended time for ANC which is supposed to be given for each woman to discuss her personal needs and for the physician to respond appropriately, especially on the first visit when a full history has to be taken and an individualized birth plan started. It was found that the mean duration of the initial visit was 10.3 (SD 2.3) minutes. If an appropriate number of physicians were available, longer durations of initial visits can be achieved even in areas with high birth rates such as Saudi Arabia [28,29]. Good performance of ANC at the studied centres also correlated with the age, language and qualifications of the physician. Younger, Arabic speaking, better qualified physicians attained better ANC performance scores, especially for health care promotion.

The study has some limitations that should be recognized. It was conducted only for 7 PHCCs, and inclusion of a greater number of centres or comparisons ofurban and rural centres was not feasible. The women's age and parity were not recorded so we were not able to determine whether these were associated with the performance of ANC. More in-depth study of the sociodemographic aspects and job satisfaction of the health care providers would also be useful to give a more accurate measure of overall performance. Inclusion of a more detailed obstetric history is also needed to determine the correlation with the pattern of ANC. In addition, observer 
bias (both that of the researchers who observed the physicians and that of the physicians who may change their behaviour in front of an observer) may have affected the results, particular the latter which may have lead to an overestimation of the completeness of their ANC care.

\section{Conclusion}

This is the first study assessing the ANC performance of physicians in PHCCs in Medina. Overall performance was fair to low, although it varied greatly across different tasks and different health centres. Having more physicians available for ANC in PHCCs could improve the standard of care. Further studies could take a more in-depth look at physicians' and nurses' characteristics and opinions to examine factors such as obstacles they face in their work place, their suggestions for improving ANC and their job satisfaction.

\section{References}

1. Di Mario S et al. What is the effectiveness of antenatal care? (Supplement). Copenhagen, World Health Organization Regional Office for Europe, 2005 (Health Evidence Network Report).

2. Reduction of maternal mortality: a joint WHO/UNFPA/UNICEF/ World Bank statement. Geneva, World Health Organization, 1999

3. Essential antenatal, perinatal and postpartum care. Training modules. Copenhagen, World Health Organization Regional Office for Europe, 2002

4. Chalmers B, Mangiaterra V, Porter R. WHO principles of perinatal care: the essential antenatal, perinatal, and postpartum care course. Birth (Berkeley, Calif.), 2001, 28:202-207.

5. 3rd Task Force Making Pregnancy Safer/Promoting Effective Perinatal Care. From evidence to practice. Verona, Italy, 22-24 October 2003. Copenhagen, World Health Organization Regional Office for Europe, 2004.

6. United Nations General Assembly. A world fit for children. Outcome document of the Special Session on Children. New York, United Nations, 2002 (A/S-27/19/Rev.1).

7. Rooney C. Antenatal care and maternal health: how effective is it? A review of the evidence. Geneva, World Health Organization, 1992 (WHO/MSM/92.4).

8. Carroli G, Rooney C, Villar J. How effective is antenatal care in preventing maternal mortality and serious morbidity? An overview of the evidence. Paediatric and Perinatal Epidemiology, 2001, 15(Suppl. 1):1-42.

9. WHO antenatal care randomized trial: manual for the implementation of the new model. Geneva, World Health Organization, 2001 (WHO/RHR/01.30).

10. Byrne DL, Asmussen T, Freeman JM. Descriptive terms for women attending antenatal clinics: mother knows best? British Journal of Obstetrics and Gynaecology, 2000, 107:12331236.

11. Antenatal care. Report of a technical working group. Geneva, 31 October-4 November 1994. Geneva, World Health Organization, 1994 (WHO/FRH/MSM/96.8).

12. Villar J et al.; WHO Antenatal Care Trial Research Group. WHO antenatal care randomised trial for the evaluation of a new model of routine antenatal care. Lancet, 2001, 357:1551-1564.

13. Villar $\mathrm{J}$ et al. The $\mathrm{WHO}$ antenatal care randomised controlled trial: rationale and study design. Paediatric and Perinatal Epidemiology, 1998, 12(Suppl. 2):27-58.

14. Byrne DL, Asmussen T, Freeman JM. Descriptive terms for women attending antenatal clinics: mother knows best? British Journal of Obstetrics and Gynaecology, 2000, 107:1233-1236.

15. Villar J, Bergsjø P. Scientific basis for the content of routine antenatal care. I. Philosophy, recent studies, and power to eliminate or alleviate adverse maternal outcomes. Acta Obstetricia et Gynecologica Scandinavica, 1997, 76:1-14.

16. Bergsjø $\mathrm{P}$, Villar J. Scientific basis for the content of routine antenatal care. II. Power to eliminate or alleviate adverse newborn outcomes; some special conditions and examinations. Acta Obstetricia et Gynecologica Scandinavica, 1997, 76:15-25.

17. Carroli G, Rooney C, Villar J. How effective is antenatal care in preventing maternal mortality and serious morbidity? An overview of the evidence. Paediatric and Perinatal Epidemiology, 2001, 15(Suppl. 1):1-42.

18. Stanton CK. Methodological issues in the measurement of birth preparedness in support of safe motherhood. Evaluation Review, 2004, 28:179-200.

19. Manandhar DS et al. Members of the MIRA Makwanpur trial team. Effect of a participatory intervention with women's groups on birth outcomes in Nepal: cluster-randomised controlled trial. Lancet, 2004, 364:970-979.

20. Kramer MS, Kakuma R. Energy and protein intake in pregnancy. Cochrane Database of Systematic Reviews, 2003, 4:CD000032.

21. Lumley J et al. Periconceptional supplementation with folate and/or multivitamins for preventing neural tube defects. $\mathrm{Co}$ chrane Database of Systematic Reviews, 2001, 3:CD001056.

22. Mahomed K, Gülmezoglu AM. Maternal iodine supplements in areas of deficiency. Cochrane Database of Systematic Reviews, 1997, 4:CD000135.

23. Atallah AN, Hofmeyr GJ, Duley L. Calcium supplementation during pregnancy for preventing hypertensive disorders and related problems. Cochrane Database of Systematic Reviews, 2002, 1:CD001059.

24. Chalmers I. Evaluating the effects of care during pregnancy and childbirth. In: Chalmers I, Enkin M, Keirse M, eds. Effective care in pregnancy and childbirth. Oxford, Oxford University Press, 1989:3-38.

25. Banta D. What is the efficacy/effectiveness of antenatal care? Copenhagen, World Health Organization Regional Office for Europe, 2003 (Health Evidence Network Report).

26. Higgins JR, de Swiet M. Blood-pressure measurement and classification in pregnancy. Lancet, 2001, 357:131-135.

27. Hodnett $E D$ et al. Home-like versus conventional institutional settings for birth. Cochrane Database of Systematic Reviews, 2005, 1:CD000012.

28. Carroli G et al.; WHO Antenatal Care Trial Research Group. WHO systematic review of randomised controlled trials of routine antenatal care. Lancet, 2001, 357:1565-1570.

29. Villar J et al. Patterns of routine antenatal care for low-risk pregnancy. The Cochrane Library, Issue No. 2. Oxford, Update Software, 2002. 